\title{
O PODER DE INOVAÇÃO E A IMPLEMENTAÇÃO DA ESTRATÉGIA PARA A SUSTENTABILIDADE NO SETOR MINERAL BRASILEIRO
}

\section{RESUMO}

O estudo analisou a relação do poder de inovação na implementação da estratégia para a sustentabilidade de empresas do setor mineral. O estudo foi conduzido por meio de um survey com empresas vinculadas ao Instituto Brasileiro de Mineração (IBRAM) e utilizou a técnica de análise de correspondência múltipla (Homals). Nesse sentido, foi possível verificar que as empresas que apresentam características de inovação e atividades ambientais possuem uma postura estratégica ofensiva em relação à sustentabilidade, investindo em aspectos ambientais e na inserção de tecnologias em seus produtos e processos.

Palavras-chave: Estratégia; Inovação; Sustentabilidade; Indústria Mineral.

\section{THE POWER OF INNOVATION OF IMPLEMENTATION STRATEGIES FOR SUSTAINABILITY IN THE BRAZILIAN MINERAL SECTOR}

\begin{abstract}
The study analyzed the relationship of the power of innovation of strategy implementation to the sustainability of mining companies. The study was conducted through a survey with companies related to the Brazilian Mining Institute (IBRAM) and used the technique of multiple correspondence analysis (HOMALS). We found that companies that exhibit characteristics of innovation and environmental activities have an offensive strategic posture in relation to sustainability, investing in environmental aspects, and in the integration of technology in their products and processes.
\end{abstract}

Keywords: Strategy; Innovation; Sustainability; Mining Industry 
EL PODER DE LA INNOVACIÓN Y ESTRATEGIA DE IMPLEMENTACIÓN PARA LA SOSTENIBILIDAD EN EL SECTOR DE LA MINERIA DE BRASIL

\section{RESUMEN}

El estudio examinó la relación entre el poder de la innovación en la implementación de la estrategia para la sostenibilidad de las empresas en el sector minero. El estudio se realizó mediante una encuesta con vinculado al Instituto Brasileño de Minería (IBRAM) las empresas y se utiliza la técnica de análisis de correspondencia múltiple (homals). En este sentido, hemos encontrado que las empresas que exhiben características de la innovación y las actividades ambientales tienen una postura estratégica ofensiva hacia la sostenibilidad mediante la inversión en aspectos medioambientales y la integración de la tecnología en sus productos y procesos.

Palabras clave: Estrategia; Innovación; Sostenibilidad; Industria Mineral.

Luciana Aparecida Barbieri da Rosa ${ }^{1}$

Clandia Maffini Gomes ${ }^{2}$

Jordana Marques Kneipp ${ }^{3}$ Roberto Schoproni Bichueti ${ }^{4}$

\footnotetext{
${ }^{1}$ Mestre em Administração pela Universidade Federal de Santa Maria - UFSM. Professora da Universidade Federal de Santa Maria - UFSM. Brasil. E-mail: lucianaaparecidabarbieri@yahoo.com.br

2 Doutora em Administração pela Universidade de São Paulo - USP. Professora do Departamento de Ciências Administrativas da Universidade Federal de Santa Maria - UFSM. Brasil. E-mail: clandia@smail.ufsm.br

${ }^{3}$ Doutoranda em Administração no Programa de Pós-Graduação em Administração da Universidade Federal de Santa Maria - UFSM. Brasil. E-mail: jordanakneipp@yahoo.com.br

${ }^{4}$ Doutorando em Administração no Programa de Pós-Graduação em Administração da Universidade Federal de Santa Maria - UFSM. Professor da Universidade Federal de Santa Maria - UFSM. Brasil. E-mail: robertobichueti@hotmail.com
} 


\section{INTRODUÇÃO}

A gestão da inovação tem se tornado um fator primordial para o sucesso e continuidade das organizações. Em outras palavras, as organizações podem obter vantagens (como, por exemplo, redução de custos, aumento da produtividade e exploração de novos mercados) garantido posições competitivas frente à concorrência como resultado de investimentos em inovação. Mais importante ainda, tem-se a questão das inovações de produto e processo que podem vir a melhorar o desempenho ambiental das empresas (Porter \& Van Der Linde, 1995; Van Bommel, 2011), visto que há uma grande visibilidade (tanto positiva quanto negativa) nos cenários nacional e internacional no que se refere às questões ambientais.

Com isso, a inovação e a sustentabilidade são resultados de um processo de aprendizagem organizacional. Os principais recursos utilizados nesse processo envolvem a informação (sobre o avanço da tecnologia, sobre os mercados, os concorrentes, as regulamentações) e o conhecimento (as competências, o know-how), em um ambiente organizacional favorável (Senge,1990). De acordo com estudos realizados na área de sustentabilidade (por exemplo, Van Bommel, 2011), o que provavelmente determina a estratégia utilizada é o poder de inovação (características da inovação e das atividades ambientais).

Dessa forma, o foco da estratégia voltada para a inovação sustentável pode ser evidenciado de três maneiras: (1), no produto; (2), no processo; e (3) no produto/processo. A escolha do foco da estratégia pode depender de diversos fatores externos e internos à empresa. Como fatores externos podem-se citar, por exemplo: o setor de atuação da empresa; e o relacionamento da empresa com a cadeia produtiva (Van Bommel, 2011). Por outro lado, como fatores internos, podem-se citar: a capacidade da empresa em aprender sobre o ambiente natural dos negócios e de

\section{O PODER DE INOVAÇÃO E A ESCOLHA DA ESTRATÉGIA PARA A SUSTENTABILIDADE}

\subsection{Estratégia}

Conforme discutido na seção anterior, inúmeras pressões nos ambientes institucional e organizacional têm demandado das empresas o estabelecimento de um processo de estratégia para a sustentabilidade. As organizações, então, podem tentar inserir a questão da inovação e da sustentabilidade na estratégia corporativa, ou então utilizar mais de uma estratégia ao mesmo tempo. Ou seja, uma estratégia corporativa e uma estratégia para a sustentabilidade. colocar em prática este conhecimento na estratégia da empresa (Van Bommel, 2011). A inovação e a sustentabilidade são resultados de um processo de aprendizagem organizacional. Os principais recursos utilizados nesse processo envolvem a informação (sobre o avanço da tecnologia, sobre os mercados, os concorrentes, as regulamentações) e o conhecimento (as competências, o know-how), em um ambiente organizacional favorável (Senge,1990).

Serão utilizadas evidências do setor mineral brasileiro devido à sua natureza produtiva/extrativa e também por seu produto ser um recurso natural nãorenovável, ou seja, existe uma modificação nas características ambientais originais provocadas pela natureza produtiva deste setor. Ao mesmo tempo em que a natureza produtiva mineral agride o meioambiente, a busca de tecnologias que minimizem esses impactos é de grande importância. Neste contexto, a extração e o processamento dos minerais, no entanto, estão associados a uma série de desafios, incluído as questões econômicas, ambientais e sociais. O principal deles consiste em mostrar que a extração, invariavelmente, proporciona vários impactos ambientais, ou seja, esgotamento dos recursos não renováveis, mudanças da flora e da fauna. Porém são essenciais para a vida cotidiana, transformando-se em inúmeros produtos utilizados pela sociedade como também em matérias-primas para as indústrias.

O objetivo do presente trabalho, logo, é o de analisar a relação do poder de inovação na implementação da estratégia para a sustentabilidade de empresas do setor mineral. O estudo foi conduzido por meio de uma survey, adotando o procedimento da análise da homogeineidade (Homals), relacionando as variáveis poder de inovação (características da atividade de inovação e da atividade ambiental) e a estratégia para a sustentabilidade empresarial em empresas industriais do setor mineral.

Para Porter (1986, p. 68) “estratégia é a criação de uma posição única e valiosa, envolvendo um conjunto de diferentes atividades". Parnell (2010) complementa que cada empresa possui sua própria estratégia e, com isso, é possível identificar grupos de empresas que executam estratégias genéricas semelhantes.

Nesta perspectiva Freeman (1974) argumenta que as organizações podem se posicionar estrategicamente em 6 (seis) maneiras diferentes (Figura 1): (1), ofensivamente; (2), defensivamente; (3), de maneira imitativa; (4), dependente; (5), tradicional; ou (6), oportunista. 
O Poder de Inovação e a Implementação da Estratégia Para a Sustentabilidade no Setor Mineral Brasileiro

\begin{tabular}{|c|l|}
\hline TIPOS DE ESTRATÉGIAS & \multicolumn{1}{c|}{ CONCEITO } \\
\hline Estratégia Ofensiva & Tem como foco a liderança tecnológica e de mercado \\
\hline Estratégia Defensiva & $\begin{array}{l}\text { Busca acompanhar as mudanças tecnológicas, porém seu objetivo não é liderar o } \\
\text { mercado }\end{array}$ \\
\hline Estratégia Imitativa & $\begin{array}{l}\text { A empresa tem interesse nas mudanças tecnológicas, mas não tem possibilidade } \\
\text { de diminuir o hiato tecnológico em relação às empresas líderes }\end{array}$ \\
\hline Estratégia Dependente & $\begin{array}{l}\text { Possui uma postura reativa, promovendo mudanças em seus produtos ou } \\
\text { processos, mediante solicitação de seus clientes }\end{array}$ \\
\hline Estratégia Tradicional & Não existe pressão de mercado e interesse da empresa para mudança \\
\hline Estratégia Oportunista & $\begin{array}{l}\text { Depende da sensibilidade do empresário em perceber uma oportunidade de } \\
\text { mercado }\end{array}$ \\
\hline
\end{tabular}

Figura 1 - Tipos genéricos de estratégia corporativa

Fonte: Adaptado de Freeman, 1974.

No que tange à tipologias estratégicas, Miles e Snow (1978) identificaram quatro estratégias genéricas de adaptação das empresas ao ambiente: defensiva, prospectiva, analítica e reativa. A estratégia defensiva possui como foco alcançar a máxima eficiência e mantém os nichos de mercado estáveis. As estratégias prospectivas são aquelas criadoras de mudanças e incertezas e buscam sempre oportunidades de mercado. As estratégias analíticas operam de duas formas: de um lado, mantêm uma base estável (rotineira), do outro lado, em mudança, buscando ideias novas. As estratégias reativas são adotadas quando as empresas percebem as mudanças, porém são incapazes de se adequar por não possuírem uma estrutura sólida.

No que se refere especificamente à relação entre a inovação na cadeia de suprimentos e a escolha da estratégia para a sustentabilidade, Van Bommel (2011), identifica três tipos resultantes: resignada, defensiva, e ofensiva. A estratégia resignada ocorre quando não se inicia o processo de implementação de sustentabilidade na cadeia de suprimento. A estratégia defensiva, por sua vez, prioriza estabelecer requisitos ambientais ao longo da cadeia. Por fim, a estratégia ofensiva busca cooperar na cadeia de suprimento com o intuito inovar orientando para sustentabilidade.

Corroborando esse pensamento, Barbieri (2011,p. 09) ressalta que:

\footnotetext{
“.... as abordagens defensiva e ofensiva são ambivalentes, ou seja, uma mesma empresa pode adotar a abordagem ofensiva para uma linha de produtos e a abordagem defensiva para outras linhas e para insumos de apoio. De acordo com Barbieri (2011), tanto a abordagem defensiva quanto a ofensiva conduzem a uma série de atividades relativas ao produto que conduzem a resultados inovadores na cadeia de suprimento, por exemplo: selos socioambientais relacionados a aspectos específicos de sustentabilidade, como comércio justo, manejo sustentável de recursos naturais, ausência de trabalho infantil etc., que se aplicam no âmbito inter e
}

intra-organizacional podendo, em alguns casos, alcançar toda a cadeia de suprimento. A estratégia defensiva, por um lado, ancorase na avaliação de fornecedores. Por outro lado, a estratégia ofensiva ancora-se no desenvolvimento de fornecedores e cooperação com a empresa focal para desenvolvimento de novos produtos e serviços sustentáveis. O impacto positivo das atividades pode ser avaliado quanto à sua contribuição à redução do impacto socioambiental negativo ou de geração de valor sustentável à cadeia de suprimento e à sociedade. Já a estratégia resignada por sua vez, de acordo com o autor, cessa as atividades."

Orsatto (2002), apresenta os tipos de estratégias ambientais que as empresas podem adotar para otimizar o retorno sobre os investimentos ambientais. O setor em que a empresa opera, seu posicionamento, tipos de mercado e suas competências determinarão o foco competitivo mais apropriado (processos organizacionais ou produtos) e a fonte potencial de vantagem competitiva (custo e diferenciação) adotadas pelas organizações.

Contudo, o atual contexto dos negócios tem influenciado as empresas se estruturarem e se adaptarem na formulação de estratégias para obtenção da vantagem competitiva, em resposta às necessidades do ambiente. A escolha da melhor estratégia pela empresa proporcionará melhoramento das práticas de gestão ambiental corporativa, reduzindo os impactos provocados pela atividade industrial.

Neste estudo será adotado o modelo de estratégias ambientais proposto por Orsatto (2002). A partir dessa tipologia será possível identificar as atividades mitigadoras das empresas do setor mineral, bem como a sua postura estratégica ambiental em relação à extração dos minerais, que ainda se deparam sendo agressivas ao meio ambiente. 


\subsection{Inovação}

Atualmente, as empresas necessitam cada vez mais envolver seus clientes com novas soluções, buscando ser competitivas perante seus concorrentes. A implementação de inovações é a maneira pela qual as empresas conseguem criar novas expectativas nos consumidores e gerar diferenciações em relação aos demais competidores (Floriani, Beuren \& Hein, 2010).

Neste contexto, Magalhães (2007, p. 42) define inovação como "toda mudança evolutiva ou disruptiva, em qualquer das dimensões competitivas, que tiver como objetivo prolongar a vida das organizações".

Outras diferentes definições de inovação, vistas sob distintas lentes (por exemplo: econômica, difusionista, científica, etc.) por diversos autores (Shumpeter, 1939; Rogers \& Shoemaker, 1982, dentre outros) podem ser apresentadas. A Figura 2 demonstra as conceituações teóricas revisadas por Vieira et al, (2008).

\begin{tabular}{|c|c|l|}
\hline AUTORES & DEFINIÇÃO & CONCEITOS/ DEFINIÇÕES \\
\hline $\begin{array}{c}\text { Schumpeter } \\
(1939)\end{array}$ & Econômica & $\begin{array}{l}\text { Define Inovação como uma função baseada em pensamento criativo } \\
\text { e ação. }\end{array}$ \\
\hline $\begin{array}{c}\text { Rogers e } \\
\text { Shoemaker }\end{array}$ & Difusionista & $\begin{array}{l}\text { Uma inovação é uma ideia, uma prática, ou um objeto percebido } \\
\text { como novo por um indivíduo }\end{array}$ \\
\hline $\begin{array}{c}\text { Rothwell e } \\
\text { Egveld (1982) }\end{array}$ & $\begin{array}{c}\text { Científica e } \\
\text { tecnológica }\end{array}$ & Inovação envolve a criação de técnicas novas e úteis. \\
\hline $\begin{array}{c}\text { Drucker } \\
(2003)\end{array}$ & Empreendedora & $\begin{array}{l}\text { Inovação é a ferramenta específica dos empreendedores, os meios } \\
\text { pelos quais são exploradas as mudanças como oportunidades para } \\
\text { novos negócios ou serviços diferentes. }\end{array}$ \\
\hline $\begin{array}{c}\text { Hyvärinem } \\
(1992)\end{array}$ & $\begin{array}{l}\text { A inovação é compreendida como fazer coisas diferentes, não } \\
\text { necessariamente em uma maneira objetiva nova. }\end{array}$ \\
\hline
\end{tabular}

Figura 2 - Definições de inovação sob diversas lentes teóricas Fonte: Adaptado de Vieira et al, 2008.

Existe uma ampla literatura (OCDE, 2005; Barbieri \& Álvares, 2003; Botelho, Carrijo \& Kamasaki, 2007; Runbach, 2007; Vila \& Kuster, 2007) sobre os tipos de inovações que podem ocorrer nas empresas, tais como: radicais, incrementais, de produto, de processo, tecnológicas, organizacionais e mercadológicas. Nesta perspectiva, Vieira et al (2008), classifica as diversas formas de inovação de acordo com as diferentes visões dos autores conforme se observa na Figura 3.

\begin{tabular}{|c|c|c|}
\hline $\begin{array}{c}\text { TIPO DE } \\
\text { INOVAÇÃO }\end{array}$ & AUTOR & DEFINIÇÃO \\
\hline \multirow[b]{2}{*}{$\begin{array}{l}\text { Inovação de } \\
\text { produto }\end{array}$} & $\begin{array}{l}\text { Sundbo e Galouj } \\
\qquad(1999) \\
\text { Bhat (2002) }\end{array}$ & $\begin{array}{l}\text { A inovação de produto reflete o processo de criação de } \\
\text { novos produtos que possuam performance superiores, preços } \\
\text { baixos, designer moderno e tamanhos cada vez menores }\end{array}$ \\
\hline & $\begin{array}{l}\text { Scannel,Vickery, } \\
\text { Droge (2000) }\end{array}$ & $\begin{array}{l}\text { É a habilidade que uma empresa tem em desenvolver novos } \\
\text { produtos ou tecnologias em respostas ás necessidades do } \\
\text { cliente, ou antecipar-se a elas e desenvolver estes mesmos } \\
\text { produtos e tecnologia antes que esta mesma necessidade se } \\
\text { torne clara. }\end{array}$ \\
\hline \multirow[b]{2}{*}{$\begin{array}{c}\text { Inovação } \\
\text { Tecnológica }\end{array}$} & Reis (2003) & $\begin{array}{l}\text { Inovação tecnológica é a introdução no mercado, com êxito, } \\
\text { de novos produtos ou tecnologias no processo de produção } \\
\text { ou nas próprias organizações. }\end{array}$ \\
\hline & Laranja (1997) & $\begin{array}{l}\text { A inovação tecnológica pode ser definida com a aplicação } \\
\text { de conhecimentos tecnológicos, que resultam em novos } \\
\text { produtos, processos ou serviços, ou uma melhora } \\
\text { significativa de seus atributos. }\end{array}$ \\
\hline $\begin{array}{l}\text { Inovação de } \\
\text { Processo }\end{array}$ & $\begin{array}{l}\text { Manual de } \\
\text { Oslo,OCDE (2004) }\end{array}$ & $\begin{array}{l}\text { São adoções de métodos de produção de produção novos ou } \\
\text { significativamente melhorados. }\end{array}$ \\
\hline
\end{tabular}




\begin{tabular}{|c|l|l|}
\hline & $\begin{array}{l}\text { Pereira e Moraes } \\
(1998)\end{array}$ & $\begin{array}{l}\text { A inovação de processo é representada pela inovação dos } \\
\text { métodos de fabricação: a disposição da linha de montagem, } \\
\text { a utilização de novas máquinas e, eventualmente, de novas } \\
\text { matérias-primas. }\end{array}$ \\
\hline $\begin{array}{c}\text { Inovação de } \\
\text { mercado }\end{array}$ & $\begin{array}{l}\text { Pereira \& Morais } \\
(1998)\end{array}$ & $\begin{array}{l}\text { Ė pura e simples descoberta de novos mercados para um } \\
\text { produto antigo é definida como sendo uma inovação de } \\
\text { mercado. }\end{array}$ \\
\hline $\begin{array}{c}\text { Inovação } \\
\text { Sistemática }\end{array}$ & Drucker (2003) & $\begin{array}{l}\text { A inovação sistemática consiste na busca deliberada e } \\
\text { organizada de mudanças, e na análise sistemática das } \\
\text { oportunidades que tais mudanças podem oferecer para a } \\
\text { inovação econômica ou social. }\end{array}$ \\
\hline
\end{tabular}

Figura 3 - Definições dos tipos de inovação

Fonte: Adaptado de Vieira et al, 2008.

Diversos autores (por exemplo: Barbieri et al, 2009; Maçaneiro \& Cunha, 2010), têm discutido a respeito de uma gestão da inovação que considere a questão da sustentabilidade. Estes autores consideram a inovação como essencial para a sustentabilidade empresarial nas dimensões ecológica, social, econômica, cultural ou espacial sem priorizar uma delas em detrimento das demais.

A implantação de inovações nos processos organizacionais apresenta um dos principais desafios gerenciais atualmente, devido às pressões no ambiente competitivo (por exemplo: regulamentações) em relação à sustentabilidade (Costa, Santos \& Oliveira, 2011).

\subsection{Sustentabilidade}

A temática da sustentabilidade surgiu, segundo Barbieri (2007, p. 92), em “meados da década de 1980, tendo como pano de fundo a crise ambiental e social que desde o início dos anos 1960 já começava a ser percebida como uma crise de dimensão planetária".

No ano de 1983, na assembleia geral da ONU, foi criada a Comissão Mundial para o Meio Ambiente e Desenvolvimento, com o objetivo de pesquisar os problemas ambientais mundiais. Em 1989, os resultados são publicados no "Relatório Brundtland", onde são criados dois conceitos "sustentabilidade" e "nova ordem mundial" (Grun, 2006).

Após o relatório do Brudtland, em 1987, a sustentabilidade foi incorporada na estratégia corporativa das empresas e em 1991, foi criada a Carta Empresarial para o Desenvolvimento Sustentável que, de acordo com Tachizawa e Andrade (2008, p.61), as "organizações necessitam partilhar o entendimento de que deve existir um objetivo comum, e não um conflito, entre desenvolvimento econômico e proteção ambiental, tanto para o momento presente, como para as gerações futuras". Corroborando, Seifert (2007) complementa que a sociedade vem percebendo que a forma que vem desenvolvendo suas atividades produtivas está provocando sérios problemas socioambientais e econômicos. Aliados a isso, impactos crescentes vêm afetando a saúde e a qualidade de vida de boa parte da população.

Neste contexto, a sustentabilidade corporativa consiste em três componentes: o ambiental, o social e o desempenho econômico. Esta perspectiva corresponde à ideia do triple bottom line, um conceito desenvolvido por Elkington (2004), que considera simultaneamente os objetivos econômicos, ambientais e sociais do ponto de vista microeconômico.

Brito e Lombardi (2007) afirmam que a temática da sustentabilidade vem sendo muito discutida atualmente. Porém, de acordo com os autores, para que essa discussão tenha significado, é necessário que as organizações e a sociedade se sensibilizarem no sentido de que o meio ambiente é finito e a sua utilização inadequada os levará a um colapso global.

Desse modo, pode-se observar que a inovação e a sustentabilidade são fundamentais no ambiente competitivo empresarial. A integração desses conceitos torna-se fundamental para a criação de novos produtos e de processos com uma visão de minimização de impactos no ambiente, garantindo a preservação ambiental às gerações futuras.

\subsection{Hipótese do Estudo}

Para analisar o poder de inovação, foram utilizados os modelos de Van Bommell (2011) e de Barbieri (2011), visando identificar de que forma a capacidade das organizações de reagir às pressões é influenciada pelo poder de inovação (característica da atividade de inovação e da atividade ambiental). Para verificar de que modo a inter-relação entre as pressões e os incentivos pode influenciar as empresas na implementação da estratégia para sustentabilidade, adotando uma postura estratégica defensiva ou ofensiva, foram adotados os estudos de Van Bommell (2011) e Orsatto (2002) .

Existem estudos que sugerem algumas características que podem evidenciar o poder de inovação na implementação da estratégia para a sustentabilidade. Van Bommell (2011), por exemplo, sugere as seguintes características: (1), orientação externa e transparência nos processos de inovação; (2), 
cooperação entre os departamentos; (3), conhecimento sobre o ambiente dos negócios e adaptação desse conhecimento à realidade da empresa; (4), liderança na introdução de novos produtos e de novos processos no mercado; (5), autonomia e lidera o mercado em relação a iniciativas inovadoras; e (6), orientação para os resultados da inovação.

A Figura 4 apresenta as definições propostas pelo autor para cada uma destas características.

\begin{tabular}{|c|l|}
\hline ATIVIDADE DE INOVAÇÃo & \multicolumn{1}{c|}{ DEFINIÇÕES } \\
\hline $\begin{array}{c}\text { Orientação externa e transparência nos } \\
\text { processos de inovação }\end{array}$ & $\begin{array}{l}\text { A empresa possui como foco a diferenciação e a } \\
\text { competição com as demais organizações. }\end{array}$ \\
\hline $\begin{array}{c}\text { Cooperação entre os departamentos } \\
\text { e adaptação desse conhecimento à realidade } \\
\text { da empresa }\end{array}$ & $\begin{array}{l}\text { A empresa proporciona a sinergia e facilita o bom } \\
\text { funcionamento de trabalho entre os departamentos. }\end{array}$ \\
\hline $\begin{array}{c}\text { Liderança na introdução de novos produtos e } \\
\text { Ae novos processos no mercado }\end{array}$ & $\begin{array}{l}\text { Organizações e adaptar-se à realidade de cada empresa. } \\
\text { competitiva realizada pela empresa na busca de novos } \\
\text { mercados. }\end{array}$ \\
\hline $\begin{array}{c}\text { Autonomia e liderança no mercado em relação } \\
\text { a iniciativas inovadoras }\end{array}$ & $\begin{array}{l}\text { A empresa busca estar atenta à busca de novas } \\
\text { tecnologias, sendo a primeira a criar novos produtos ou } \\
\text { melhorias do processo. }\end{array}$ \\
\hline Orientação para os resultados da inovação & $\begin{array}{l}\text { A empresa busca obter lucros ou algum tipo de } \\
\text { resultado, tendo como foco a inovação. }\end{array}$ \\
\hline
\end{tabular}

Figura 4 - Características de atividade de inovação nas empresas

Fonte: Adaptado de Van Bommel, 2011.

Além das características das atividades de inovação, outra variável que provavelmente influencia na escolha da estratégia ambiental são as características das atividades ambientais. A escolha de cada uma delas, irá determinar o tipo de estratégia empresarial. Por exemplo, aquelas atividades em que a empresa atua de maneira isolada incorporando aspectos sociais e ambientais, buscando reduzir custos e impactos ambientais no processo produtivo a partir de pressões externas (por exemplo: políticas públicas, legislação, etc.) podem influenciar a adoção de uma estratégia defensiva voltada para a sustentabilidade. Por outro lado, aquelas atividades sustentáveis que auxiliam a empresa na busca de reduzir os impactos ambientais no processo produtivo e o envolvimento dos stakeholders, buscando ir além da conformidade com a legislação podem influenciar a adoção de uma estratégia ofensiva voltada para a sustentabilidade, como mostra a Figura 5.

\begin{tabular}{|c|l|}
\hline $\begin{array}{c}\text { ATIVIDADES } \\
\text { AMBIENTAIS }\end{array}$ & \multicolumn{1}{c|}{ DESCRIÇÃo } \\
\hline \multirow{3}{*}{ Produto/Organização } & $\begin{array}{l}\text {-O desenvolvimento sustentável como prioridade no projeto, operação e } \\
\text { encerramento das operações das minas. } \\
\text { - Avaliação global e periódica dos impactos ambientais diretos e indiretos } \\
\text { da atividade empresarial nos ecossistemas e na comunidade desde o projeto, } \\
\text { exploração até o fechamento da mina }\end{array}$ \\
\hline Iniciativas multi-stakeholder & $\begin{array}{l}\text { - Incentivos aos stakeholders (clientes, fornecedores, empregados, } \\
\text { comunidade etc.) para a adoção de práticas e princípios baseados na } \\
\text { - Divulgação para os stakeholders (clientes, fornecedores, empregados, } \\
\text { comunidade etc.) do seu desempenho econômico, social e ambiental e da } \\
\text { sua contribuição para o desenvolvimento sustentável. }\end{array}$ \\
\hline Esquemas abertos & $\begin{array}{l}\text { - Sistema de gestão ambiental a fim de avaliar, prevenir ou mitigar os } \\
\text { impactos ambientais adversos. } \\
\text { - Certificações ambientais como ISO 14001/SA 8000. }\end{array}$ \\
\hline
\end{tabular}




\begin{tabular}{|c|l|}
\hline $\begin{array}{c}\text { Diretrizes gerais/Códigos de } \\
\text { conduta }\end{array}$ & $\begin{array}{l}\text { - Políticas e práticas comerciais éticas. } \\
\text { - Integração dos princípios do desenvolvimento sustentável às suas práticas } \\
\text { e políticas. }\end{array}$ \\
\hline
\end{tabular}

Figura 5 - Características das Atividades Ambientais

Fonte: Adaptado de Van Bommel, 2011, Barbieri ,2011.

Portanto, o modelo conceitual proposto encontra-se baseado em uma hipótese geral:

O poder de inovação está relacionado com a implementação de uma estratégia de sustentabilidade empresarial.

\section{MÉTODO DO ESTUDO}

\subsection{Abordagem de Pesquisa}

A pesquisa caracteriza-se como quantitativa e foi conduzida por meio de um survey, com a aplicação de um questionário estruturado em empresas industriais do setor mineral. O procedimento adotado foi a análise da homogeneidade (Homals), relacionando as variáveis poder de inovação (características da atividade de inovação e da atividade ambiental) e a estratégia para a sustentabilidade empresarial.Segundo Pestana e Gageiro (2003, p. 483), essa técnica "permite estudar a relação entre mais do que duas variáveis nominais e representá-la em poucas dimensões".

O universo da pesquisa foi constituído de empresas industriais do setor mineral associadas ao IBRAM, totalizando duzentos e sessenta (260) empresas pesquisadas. A escolha dessa população como objeto de investigação, decorre do fato do setor ser representativo na economia brasileira e possuir grandes desafios no que se refere ao desenvolvimento sustentável, tendo em vista algumas particularidades como sua natureza extrativa e utilização de recursos não renováveis. A coleta de dados foi realizada por meio de questionário estruturado no período de outubro de 2011 a outubro de 2012 enviado por e-mail às empresas objeto de estudo. Os dados foram tabulados e analisados com o auxílio dos softwares Microsoft Excel e Statistical Package for the Social Sciences SPSS, por meio da adoção de modelos de análise multivariados. Obteve-se um retorno de 51 questionários, representando $20 \%$ da população pesquisada.

\subsection{Modelo Conceitual}

O objetivo deste trabalho é o de estudar a relação do poder de inovação na implementação da estratégia para a sustentabilidade de empresas do setor mineral.

Nesse sentido, de acordo com alguns autores (por exemplo, Van Bommell, 2011), a escolha da estratégia $(y)$ pode ser (provavelmente) influenciada por duas variáveis: a gestão da inovação, mais precisamente as características de inovação $\left(x_{i}\right)$ (por exemplo: orientação externa e transparência nos processos de inovação; liderança na introdução de novos produtos); e as atividades sustentáveis $\left(x_{i i}\right)$ (por exemplo: código de conduta, certificações, etc.). A partir dos conceitos e informações obtidos na fundamentação teórica, com base nos estudos de Van Bommell (2011), Barbieri (2011) e Orsatto (2002), foi construído o modelo conceitual foi elaborado o modelo conceitual da pesquisa, o qual contempla as variáveis apresentadas na Figura 6. 


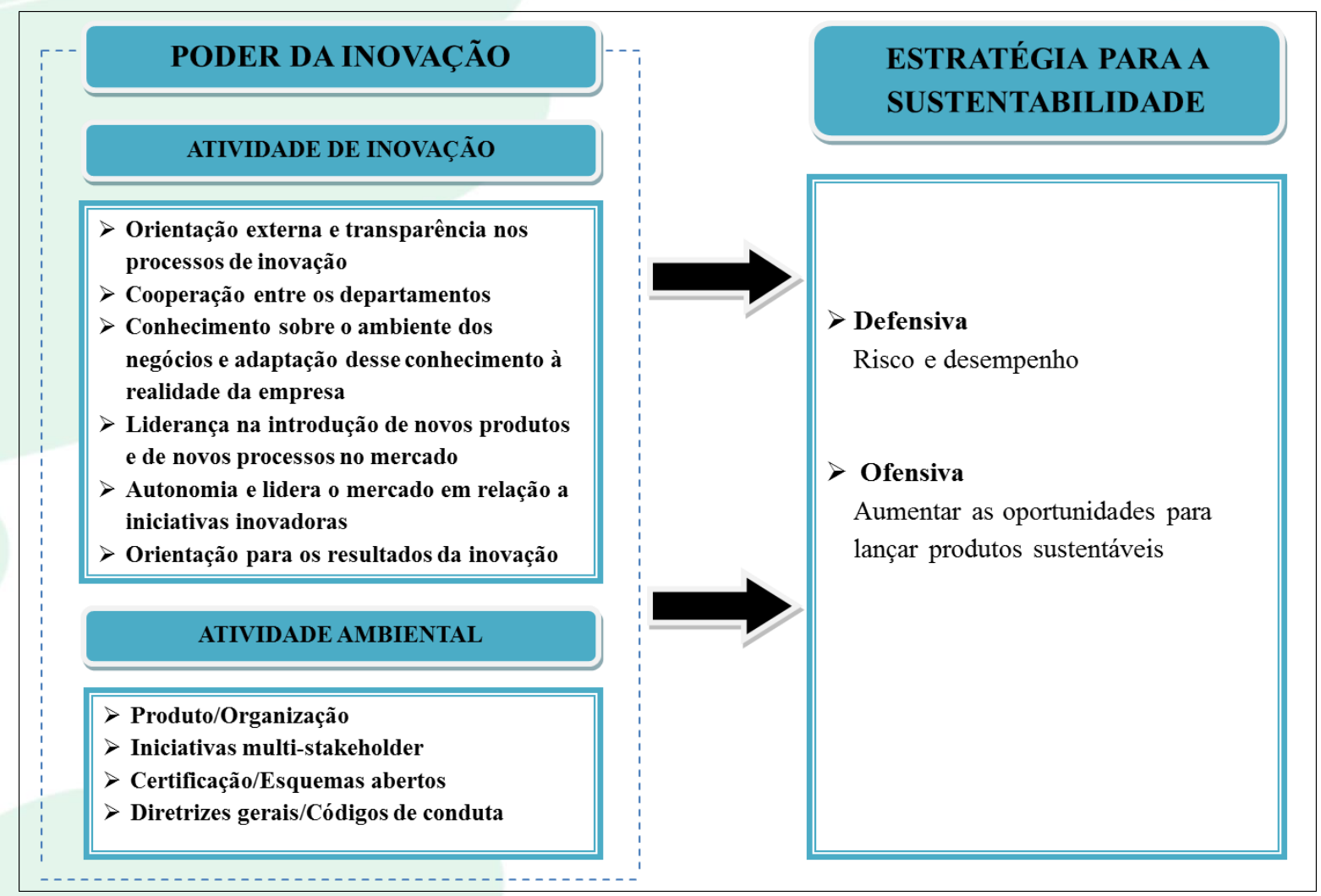

Figura 6 - Modelo conceitual da pesquisa

Fonte: Adaptado de Van Bommel, 2011, Barbieri ,2011, Orsato, 2002.

\subsection{Operacionalização das Variáveis}

Na fase quantitativa, a operacionalização das variáveis foi fundamentada em três blocos (macrovariáveis). Em relação ao primeiro bloco, encontram-se a variável independente sobre características de inovação. No segundo bloco, a variável independente referente às atividades ambientais e, por fim, no terceiro bloco, a variável dependente sobre a estratégia para sustentabilidade. Para a fase qualitativa, as categorias de análises foram operacionalizadas por meio das variáveis da fase quantitativa.

$\mathrm{Na}$ figura 7, são apresentadas as descrições de cada variável deste estudo.

\begin{tabular}{|l|l|}
\hline \multicolumn{1}{|c|}{ DIMENSÕES } & \multicolumn{1}{c|}{ VARIÁVEIS } \\
\hline Tipos de Estratégias & Dependente \\
\hline Característica de Inovação & Independente \\
\hline Atividades sustentáveis & Independente \\
\hline
\end{tabular}

Figura 7 - Operacionalização das variáveis

\subsection{Coleta e análise dos dados}

O estudo foi conduzido por meio de uma pesquisa survey, no período de outubro de 2011 a outubro de 2012, com a aplicação de um questionário estruturado, em quatro blocos: perfil do respondente, caracterização da empresa, potencial de inovação, atividades ambientais, estratégias para a sustentabilidade com as empresas associadas ao IBRAM ). Para a análise de dados, foi utilizada uma escala intervalar, na qual os respondentes deveriam assinalar o grau (nota) que melhor traduzia a sua concordância em relação às ações adotadas pela empresa, no intervalo entre 0,1 (menor grau de concordância) e 1 (máxima concordância). $\mathrm{O}$ algarismo 0 (zero) representava a opção não se aplica.A escala utilizada neste estudo foi validada em uma dissertação 
O Poder de Inovação e a Implementação da Estratégia Para a Sustentabilidade no Setor Mineral Brasileiro

de mestrado de autoria de Kneipp (2012), buscando analisar a influência da gestão para a sustentabilidade no desempenho em empresas do setor mineral.

O questionário foi estruturado com base no modelo conceitual de pesquisa. Após esta etapa, foi encaminhado para avaliação de especialistas na área, para fins de validação. Depois desses procedimentos, os questionários foram direcionados por meio de e-mail aos responsáveis pela área de inovação e sustentabilidade das empresas.
Os dados da etapa quantitativa foram tabulados e analisados a partir da aplicação de técnicas de análise univariadas, bivariadas e multivariadas com o auxílio dos softwares (Excel e SPSS).

\section{ANÁLISE E DISCUSSÃO DOS RESULTADOS}

4.1 Caracterização das Empresas Estudadas

\begin{tabular}{|l|l|}
\hline \multicolumn{1}{|c|}{$\begin{array}{c}\text { CARACTERÍSTICAS } \\
\text { ORGANIZACIONAIS (MÉDIA) }\end{array}$} & \multicolumn{1}{c|}{ DADOS } \\
\hline Tempo de fundação & 37 anos \\
\hline Principais produtos & Agregados minerais, o carvão mineral, o calcário e o ferro \\
\hline Número de empregados & De 100 a 499 empregados (média empresa) \\
\hline Receita operacional bruta & $\begin{array}{l}\text { Acima de R } \$ 2,4 \text { milhões R } \$ 90 \text { milhões (pequena e média } \\
\text { empresa) }\end{array}$ \\
\hline Introdução de inovação & Produto e em processo \\
\hline $\begin{array}{l}\text { Responsabilidade da inovação na } \\
\text { empresa }\end{array}$ & A empresa é a única responsável pela atividade de inovação \\
\hline
\end{tabular}

Figura 8 - Resumo do perfil predominante das empresas Fonte: Resultados da pesquisa (2013).

De acordo com a Figura 8, é possível verificar que as empesas possuem média de existência é 37 anos, têm elevado grau de maturidade e produzem agregados minerais, carvão mineral, calcário e ferro e caracterizam-se ainda como de médio e pequeno porte. A inovação em produto e em processo, de forma simultânea, faz parte do comportamento tecnológico da maior parte das empresas deste estudo.

Os resultados expostos revelam que a maioria das empresas considera ser a principal responsável pela atividade de inovação. Esse fato pode ser explicado pela natureza da atividade extrativa, ou seja, o produto considerado bruto apresenta pouco valor agregado.

Em suma, é possível depreender que as empresas do setor mineral analisadas, em sua maioria, apresentam o seguinte perfil: têm elevada variabilidade em relação ao tempo de atuação, têm como principal produto os agregados minerais, médio e grande porte e inovam em produto e processo.

\subsection{Análise de Correspondência Múltipla ( Homals)}

A fim de verificar a relação existente entre as variáveis poder de inovação (atividade de inovação $e$ atividade ambiental) e estratégia para a sustentabilidade, foi realizada uma análise de correspondência múltipla (Homals). As novas variáveis geradas foram divididas em duas categorias de análise de acordo com a Figura 9: 
O Poder de Inovação e a Implementação da Estratégia Para a Sustentabilidade no Setor Mineral Brasileiro

\begin{tabular}{|c|c|}
\hline VARIÁVEIS & INDICADORES \\
\hline Estratégia & $\begin{array}{c}\text { Defensiva } \\
\text { Ofensiva }\end{array}$ \\
\hline Orientação Externa & \multirow{14}{*}{$\begin{array}{l}\text { Alta } \\
\text { Baixa }\end{array}$} \\
\hline Cooperação entre departamentos & \\
\hline Conhecimento do ambiente & \\
\hline Liderança na introdução & \\
\hline Autonomia e lidera & \\
\hline Orientação para resultados & \\
\hline Desenvolvimento sustentável & \\
\hline Avaliação global & \\
\hline Incentivos stakerolders & \\
\hline Divulgação de seu desempenho & \\
\hline Sistema gestão ambiental & \\
\hline Certificações ambientais & \\
\hline Políticas e práticas ambientais & \\
\hline \begin{tabular}{|l|} 
Integração dos princípios \\
\end{tabular} & \\
\hline
\end{tabular}

Figura 9 - Modelo inicial da análise de regressão múltipla (Homals).

Fonte: Resultados da pesquisa (2013).

Com as análises realizadas, foi observado que a dimensão 1 possui eigenvalue (autovalores) de 5,615 e a dimensão 2, o valor de 2,874. Os autovalores informam sobre a contribuição de cada dimensão, explicando a variabilidade contida nos dados ( Pestana e Gageiro, 2003). Na Tabela 1, é possível observar as medidas de discriminação das variáveis que mais contribuem para a definição de cada dimensão

Tabela 1 - Medidas de discriminação das variáveis

\begin{tabular}{|c|c|c|}
\hline \multirow{2}{*}{ VARIÁVEIS } & \multicolumn{2}{|c|}{ ESCORES } \\
\hline & DIMENSÃO 1 & DIMENSÃO 2 \\
\hline Orientação Externa & 0,525 & 0,189 \\
\hline Cooperação entre departamentos & 0,486 & 0,139 \\
\hline Conhecimento do ambiente & 0,345 & 0,127 \\
\hline Liderança na introdução & 0,131 & 0,611 \\
\hline Autonomia e liderança & 0,192 & 0,572 \\
\hline Orientação para resultados & 0,237 & 0,303 \\
\hline Desenvolvimento sustentável & 0,518 & 0,171 \\
\hline Avaliação global & 0,535 & 0,153 \\
\hline Incentivos stakerolders & 0,333 & 0,050 \\
\hline Divulgação de seu desempenho & 0,482 & 0,007 \\
\hline Sistema gestão ambiental & 0,382 & 0,307 \\
\hline Certificações ambientais & 0,333 & 0,103 \\
\hline Políticas e práticas ambientais & 0,327 & 0,008 \\
\hline Integração dos princípios & 0,652 & 0,100 \\
\hline
\end{tabular}

Na Figura 10, são apresentadas as relações de correspondência entre as categorias atividade de inovação e atividade ambiental e estratégia. 


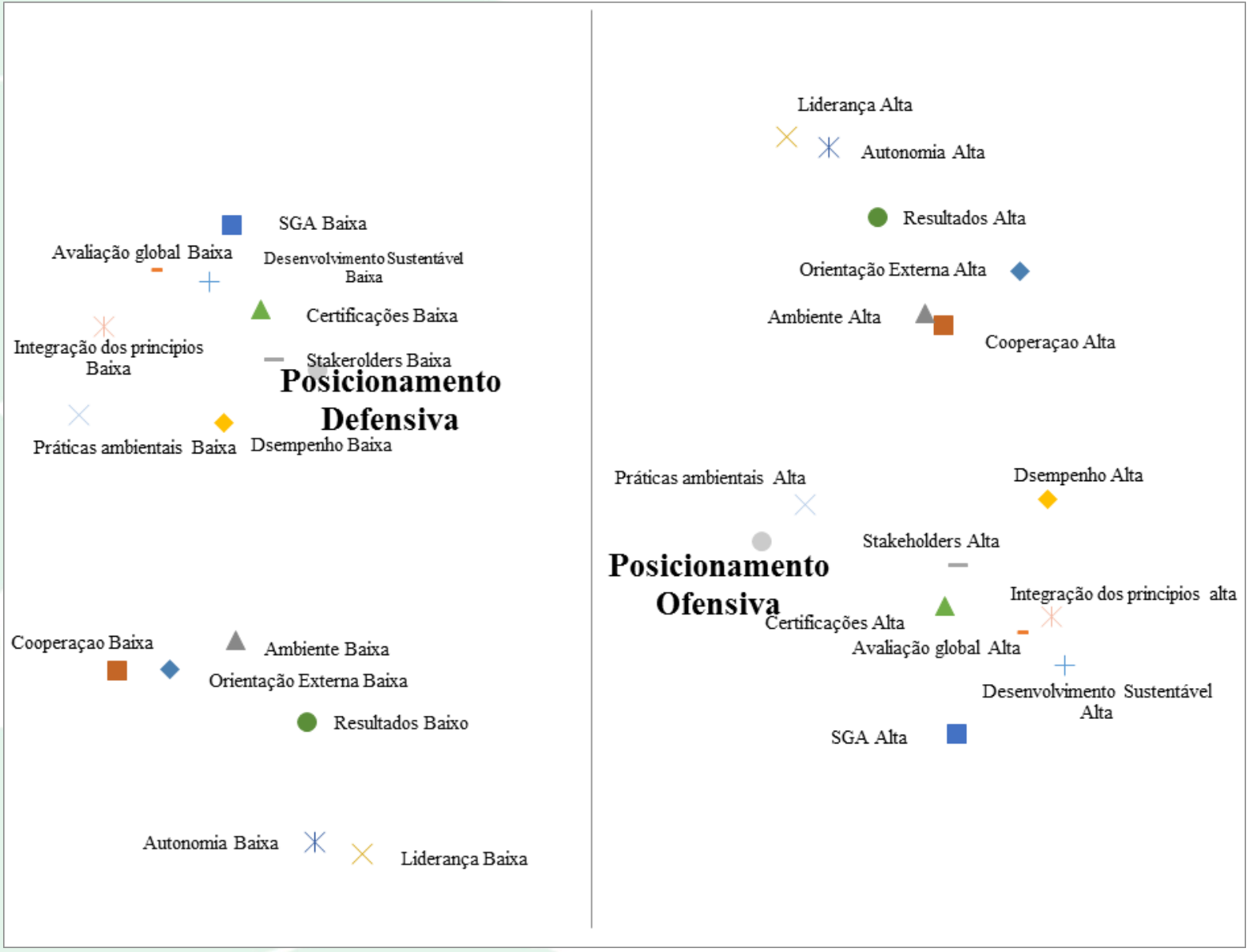

Figura 10 - Correspondência entre as categorias

Fonte: Resultados da pesquisa (2013).

Os dados apresentados no Figura 10, permitem efetuar algumas considerações a respeito da relação o poder de inovação e o posicionamento estratégico, que serão apresentados na Figura 11, com a postura estratégica defensiva e ofensiva das empresas analisadas. 


\begin{tabular}{|c|c|c|c|}
\hline \multirow{2}{*}{ CONSTRUTO } & \multirow{2}{*}{ VARIÁVEIS } & \multicolumn{2}{|c|}{ POSTURA ESTRATÉGICA } \\
\hline & & DEFENSIVA & OFENSIVA \\
\hline \multirow{6}{*}{ 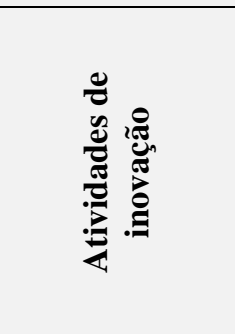 } & Orientação Externa & Baixa & Alta \\
\hline & $\begin{array}{l}\text { Cooperação entre } \\
\text { departamentos }\end{array}$ & Baixa & Alta \\
\hline & $\begin{array}{l}\text { Conhecimento do } \\
\text { ambiente }\end{array}$ & Baixa & Alta \\
\hline & Liderança na introdução & Baixa & Alta \\
\hline & Autonomia e lidera & Baixa & Alta \\
\hline & Orientação para resultados & Baixa & Alta \\
\hline \multirow{7}{*}{ 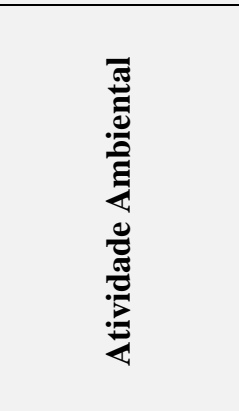 } & \begin{tabular}{c|}
$\begin{array}{c}\text { Desenvolvimento } \\
\text { sustentável }\end{array}$ \\
\end{tabular} & Baixa & Alta \\
\hline & Avaliação global & Baixa & Alta \\
\hline & Incentivos stakeholders & Baixa & Alta \\
\hline & $\begin{array}{l}\text { Divulgação de seu } \\
\text { desempenho }\end{array}$ & Baixa & Alta \\
\hline & \begin{tabular}{|l|} 
Sistema gestão ambiental \\
\end{tabular} & Baixa & Alta \\
\hline & Certificações ambientais & Baixa & Alta \\
\hline & $\begin{array}{c}\text { Políticas e práticas } \\
\text { ambientais }\end{array}$ & Baixa & Alta \\
\hline
\end{tabular}

Figura 11 - Postura estratégica defensiva e ofensiva das empresas Fonte: Resultados da pesquisa (2013).

Uma empresa, para se estabilizar no mercado, necessita implementar estratégias competitivas que resultem na busca dos seus objetivos. No entanto, as estratégias empresariais implementadas pelas empresas determinam sua postura. De acordo com a figura 11, foi possível verificar duas posturas estratégicas: defensiva e ofensiva.

As empresas com perfil estratégico defensivo apresentam todos os indicadores referentes às características de inovação e à característica de atividade ambiental com intensidade baixa. Notam-se, nesse tipo de empresa, algumas características referentes à sua postura conservadora: atua em mercados mais seguros, não lidera na introdução de novas tecnologias, possui comportamento mais conservador no investimento de práticas ambientais (Van Bommell,2011; Orsatto,2002).

Observa-se que as empresas com postura ofensiva, ao contrário, apresentam todas as variáveis referentes à atividade de inovação e atividade ambiental com intensidade alta. Os dados evidenciam uma flexibilidade dessas empresas, buscando oportunidades de mercado, bem como a inserção, em suas estratégias, dos princípios da sustentabilidade. Evidenciam-se, nesse tipo de empresa, algumas características desta postura, tais como investimento em tecnologias ambientais; inovações em produto ou em processo (Van Bomnell,2011; Orsatto,2002).

Portanto, a partir da análise de correspondência múltipla (Homals), que mostrou a associação entre o alto poder de inovação com a estratégia ofensiva para a sustentabilidade, é possível confirmar a hipótese proposta com base nos modelos de Van Bommel (2011) e Orsatto (2002):
O poder de inovação está relacionado com a implementação de uma estratégia de sustentabilidade empresarial.

\section{CONSIDERAÇÕES FINAIS}

Esta pesquisa teve como objetivo analisar a relação do poder de inovação na implementação da estratégia para a sustentabilidade de empresas do setor mineral

A fim de atingir o objetivo do estudo, foi realizada uma análise de correspondência múltipla (Homals). Nesse sentido, foi possível concluir que as empresas que apresentam características de inovação e atividades ambientais de alta intensidade possuem uma postura estratégica ofensiva em relação à sustentabilidade, investindo em aspectos ambientais e na inserção de tecnologias em seus produtos e processos. A adoção de tal postura se deve ao fato de que essas práticas realizadas pelas empresas provavelmente lhes conferem maior competitividade.

Diante deste exposto, o atual contexto dos negócios tem influenciado as empresas a se estruturarem e se adaptarem na formulação de estratégias para obtenção da vantagem competitiva, em resposta às necessidades do ambiente. A escolha da melhor estratégia pela empresa proporcionará melhoramento das práticas de gestão ambiental corporativa, reduzindo os impactos provocados pela atividade industrial.

Desse modo, pode-se observar que a inovação e a sustentabilidade são fundamentais no ambiente 
competitivo empresarial. A integração desses conceitos torna-se fundamental para a criação de novos produtos e de processos com uma visão de minimização de impactos no ambiente, garantindo a preservação ambiental às gerações futuras.

Os fatores limitantes desse estudo se referem ao número de empresas que se disponibilizaram a responder ao questionário, tornando a amostra pouco representativa em relação à população pesquisada. Desse modo, não é possível generalizar os resultados encontrados em relação às empresas do setor. As conclusões relatadas neste estudo referem-se, portanto,

\section{REFERÊNCIAS}

Barbieri., J. C (2007). Gestão Ambiental Empresarial: conceitos, modelos instrumentos. 2 ed. São Paulo: Saraiva.

Barbieri, J. C.; \& Álvares, A. C. T. (2003).Inovações nas organizações empresariais. In: Barbieri, J. C. (Org.). Organizações inovadoras: estudos e casos brasileiros. Rio de Janeiro: Editora FGV. v. 1, $1^{\circ}$ ed., $158 \mathrm{p}$.

Barbieri, J.; Vasconcelos, I.; Andreassi, T.; \& Vasconcelos, F. (2010). Inovação e Sustentabilidade: Novos Modelos e Proposições. RAE, São Paulo.

Barbieri,J. (2011). Inovação gerando sustentabilidade e oportunidades na cadeia de suprimento do setor de cosméticos no Brasil: um estudo de caso. In: ALTEC, 14,2011, Lima-Peru. Anais. Peru: ALTEC.

Beuren, I. M. (2003). Como elaborar trabalhos monográficos em contabilidade. São Paulo: Atlas.

Botelho, M. dos R. A., Carrijo, M. DE C., \& Kamasaki, G. Y. (2007). Inovações, pequenas empresas e interações com instituições de ensino/pesquisa em arranjos produtivos locais de setores de tecnologia avançada. Revista Brasileira de Inovação, v. 06,n.2,p 331- 371, jul / dez.

Brito,E.Z.; \& Lombardi, M.S. (2007). Desenvolvimento sustentável como fator de competitividade. In: ENANPAD, 31,2007, Rio de Janeiro. Anais. Rio de Janeiro: ANPAD.

Costa, A. C.V. DA; Santos,C. DE F.S.O; \& Oliveira, V. M. DE. (2011). Indicadores de Ecoinovação e Competitividade Sistêmica: Construindo Relações. In: ENANPAD, 35,Rio de Janeiro. Anais. Rio de Janeiro: ANPAD. somente às empresas participantes da amostra. Outra limitação refere-se ao porte das empresas pesquisadas na survey, em sua maioria, de pequeno e de médio porte. A presença mais efetiva de empresas de maior porte poderia trazer outros elementos importantes para a análise.

Como sugestão para estudos futuros, com o intuito de aprofundar os estudos aqui apresentados, recomenda-se a ampliação do número de empresas pesquisadas, como também ampliar a análise, buscando comparar o setor brasileiro com outros países.

Departamento Nacional de Produção Mineral - DNPM. (2012). Economia Mineral. Disponível em: http://www.dnpm.gov.br/conteudo.asp?IDSecao=68 . Acesso em:26/03/2012.

Elkington, J. (2004). Enter the Triple Bottom Line. in Adrian Henriques and Julie Richardson (ed) The Triple Bottom Line: does it all add up. EarthScan: London UK.

Floriani, R.; Beuren, I. M.; \& Hein, N. (2010). Análise comparativa da evidenciação de aspectos de inovações em empresas construtoras e multisetoriais. Revista de Gestão da Tecnologia e Sistemas de Informação, v. 7, n. 3, p. 691-710.

Freeman, C. (1974). Economics of Industrial Innovation, Penguin: Middlesex.

Grün, Mauro. (2006). Ética e educação ambiental - A conexão necessária. 10 edição. Campinas, SP: Papirus.

Hair Jr., J. F.; Anderson, R. E.; Tatham, R. L.; \& Black, W. C. (2005). Análise multivariada de dados. 5. ed. Porto Alegre: Bookman.

Instituto Brasileiro de Mineração - IBRAM. (2010). Relação de Associados. Disponível em: <http://www.ibram.org.br/>. Acesso em 05 de novembro de 2011.

Kneipp, J.M. (2012). Gestão para a sustentabilidade e desempenho em empresas do setor mineral. 2012. Dissertação (Mestrado). Programa de PósGraduação em Administração, Universidade Federal de Santa Maria - UFSM, Santa Maria.

Leal, C.E. (2009). A era das organizações sustentáveis. Revista Eletrônica Novo Enfoque, Rio de Janeiro, v. $8, \quad$ n. 8 . Disponível em: <http://www.castelobranco.br/sistema/novoenfoque >. Acesso em: $09 / 01 / 2012$. 
Maçaneiro, M. B.; \& Cunha, S. K. (2010). EcoInovação: um quadro de referências para pesquisas futuras. In:Simpósio de Gestão da Inovação Tecnológica, 26, 2010, Vitória.Anais. Brasilia: ANPAD.

Magalhães, M. F. (2007).Inovando para durar. Inovação Quebrando Paradigmas para Vencer. São Paulo: Saraiva.

Miles, R. E., \& Snow, C. C. (1978). Organizational strategy, structure and process. New York: Mc Graw Hill.

OCDE. (2005). Manual de Oslo: diretrizes para coleta e interpretação de dados sobre inovação. $3^{\mathrm{a}}$ ed. FINEP: Rio de Janeiro.

Orsato, R. (2002). Posicionamento Ambiental Estratégico: Identificando quando vale a pena investir no verde. REAd, n. 30, vol. 6, set / dez.: 1146.

Pestana, M. H.; \& Gageiro, J. N. (2003). Análise de dados para ciências sociais: a complementaridade do SPSS, 3 ed. Edições Silabo: Lisboa.

Porter, M. E.; \& Van Der Linde, C. (1995). Toward a new conception of the environment-competitiviness relationship? In: Stavins, R. (Ed.). Economics of the environment: secelted readings. New York: W. W. Norton \& Company.

Porter, M. (1986). Estratégia Competitiva: Técnicas para a Análise de Indústrias e da Concorrência. Campus: Rio de Janeiro.
Runbach, C. V. (2007). Fomentando a inovação radical em uma organização focada em resultados. In: Terra, J. C. C (Org.). Inovação quebrando paradigmas para vencer.. São Paulo: Saraiva.

Seiffert, M.E.B. (2007). Gestão ambiental: instrumentos, esferas de ação e educação ambiental. São Paulo: Atlas.

Senge, P. (1990). The fifth discipline: the art and practice of the learning organization. Nova York: Doubleday.

Tachizawa, T , \& Andrade, R. (2008). Gestão Socioambiental: estratégias na nova era da sustentabilidade. Rio de Janeiro: Elsevier.

Van Bommel, H.W.M. (2011). A conceptual framework for analyzing sustainability strategies in industrial supply networks from an innovation perspective. Journal of Cleaner Production, v. 19, p. 895-904.

Vieira, E.M.; Perez, G.; Freire,C.A.T.; Freire,C.R.T.; Chaves,L.A.; \& Luz, R.M. (2008). Gestão da inovação nos setores de biotecnologia e biomedicina: um estudo exploratório. In: Simpósio de Inovação Tecnológica, 25, 2008. Anais: Brasília, ANPAD.

Vila, N.; \& Kuster, I. (2007). The importance of innovation in international textile firms. European Journal of Marketing,v. 41, n. 2, p. 17-36.

WCED- (World Commission on Environment and Development). (1987). Our common future. Oxford: University Press. 